\title{
Inhibition of gastric emptying and intestinal transit in anesthetized rats by a Tityus serrulatus scorpion toxin
}

\author{
L.E.A. Troncon ${ }^{1}$, \\ A.A. Santos ${ }^{2}$ \\ V.L. Garbacio ${ }^{3}$, \\ M. Secaf ${ }^{1}$, \\ A.V. Verceze ${ }^{1}$ and \\ J.R. Cunha-Melo ${ }^{3}$
}

\author{
${ }^{1}$ Departamento de Clínica Médica, Faculdade de Medicina de Ribeirão Preto, \\ Universidade de São Paulo, Ribeirão Preto, SP, Brasil \\ 2Departamento de Fisiologia e Farmacologia, Faculdade de Medicina, \\ Universidade Federal do Ceará, Fortaleza, CE, Brasil \\ ${ }^{3}$ Departamento de Cirurgia, Faculdade de Medicina, \\ Universidade Federal de Minas Gerais, Belo Horizonte, MG, Brasil
}

\section{Correspondence \\ L.E.A. Troncon \\ Departamento de Clínica Médica \\ Hospital das Clínicas, FM RP, USP \\ 14048-900 Ribeirão Preto, SP \\ Brasil \\ Fax: + 55-16-633-6695 \\ E-mail: ledatron@fmrp.usp.br \\ Presented at the XIII Annual Meeting of the Federação de Sociedades de Biologia Experimental, Caxambu, MG, Brasil, August 26-29, 1998. \\ Research supported by CNPq, FAEPA and FAPEMIG. Publication supported by FAPESP.}

Received December 17, 1999 Accepted June 21, 2000

\section{Abstract}

The effects of a fraction (T1) of Tityus serrulatus scorpion venom prepared by gel filtration on gastric emptying and small intestinal transit were investigated in male Wistar rats. Fasted animals were anesthetized with urethane, submitted to tracheal intubation and right jugular vein cannulation. Scorpion toxin $(250 \mu \mathrm{g} / \mathrm{kg})$ or saline was injected $i v$ and $1 \mathrm{~h}$ later a bolus of saline $(1.0 \mathrm{ml} / 100 \mathrm{~g})$ labeled with $99 \mathrm{~m}$ technetium-phytate $(10 \mathrm{MBq})$ was administered by gavage. After $15 \mathrm{~min}$, animals were sacrificed and the radioactivity remaining in the stomach was determined. Intestinal transit was evaluated by instillation of a technetium-labeled saline bolus $(1.0 \mathrm{ml})$ through a cannula previously implanted in the duodenum. After $60 \mathrm{~min}$, the progression of the marker throughout 7 consecutive gut segments was estimated by the geometric center method. Gastric retention of the liquid test meal in rats injected with scorpion toxin (median: $88 \%$; range: $52-95 \%$ ) was significantly higher $(\mathrm{P}<0.02)$ than in controls $(54 \% ; 21-76 \%)$, an effect which was not modified by gastric secretion blockade with ranitidine. The progression of the isotope marker throughout the small intestine was significantly slower $(\mathrm{P}<0.05)$ in rats treated with toxin $(1.2 ; 1.0-2.5)$ than in control animals $(2.3 ; 1.0-3.2)$. Inhibition of both gastric emptying and intestinal transit in rats injected with scorpion toxin suggests an increased resistance to aboral flow, which might be caused by abnormal neurotransmitter release or by the local effects of venom on smooth muscle cells.

\section{Introduction}

Envenomation with scorpion toxin may produce a range of clinical manifestations related to the gastrointestinal tract, including salivation, epigastric pain, vomiting and diarrhea (1). Injection of purified scorpion toxin in rats induces a dramatic increase in gastric

\section{Key words}

- Scorpion toxin

- Gastric emptying

- Intestinal transit

- Gastrointestinal motility 
serrulatus induces a sustained slowing of gastric emptying in rats (6).

Despite the clinical and experimental evidence that tityustoxin may influence the gastrointestinal tract and produce striking motor effects, its influence on gastrointestinal transit has not been extensively investigated. In the present study, we show that injection of a partially purified fraction from T. serrulatus venom in anesthetized rats is followed by a remarkable inhibition not only of gastric emptying but also of small intestinal transit.

\section{Material and Methods}

\section{Animals}

Seventy-four male Wistar rats weighing 190-270 g were housed in individual Bollman cages. Solid food was denied for $18 \mathrm{~h}$ before the experiments, but the animals were allowed to drink a $10 \%$ dextrose solution ad libitum.

\section{Toxin injection}

With the exception of an experiment carried out to determine the pattern of intestinal transit in awake rats, all other studies were performed on animals anesthetized with an intraperitoneal injection of urethane $(1.5 \mathrm{~g} /$ $\mathrm{kg})$. Subsequently, the trachea and the right jugular vein were cannulated with polyethylene catheters and the animals were injected $i v$ with saline (controls) or with the partially purified $\mathrm{T} 1$ fraction from the $T$. serrulatus scorpion venom $(250 \mu \mathrm{g} / \mathrm{kg})$. This fraction was obtained by Sephadex G-25 chromatography (7) and was kindly provided by Prof. T. Morais Santos (School of Pharmacy, UFMG, Belo Horizonte, MG, Brazil). The partially purified $\mathrm{T} 1$ fraction was lyophilized and transported under ice to Ribeirão Preto (SP, Brazil) and kept at $-20^{\circ} \mathrm{C}$ until utilized. All experiments were performed in the afternoon.

\section{Gastric emptying}

Gastric emptying was assessed by determining the fractional radioactivity present in the stomach after intragastric instillation of saline $(1.0 \mathrm{ml} / 100 \mathrm{~g})$ labeled with $10 \mathrm{MBq}$

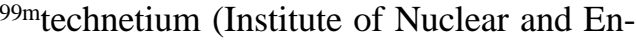
ergetic Research - IPEN, São Paulo, SP, Brazil) coupled to phytate ("Phytosid", Sydma Medical Reagents and Equipments, Ribeirão Preto, SP, Brazil), as an unabsorbable carrier. Two groups of rats were anesthetized and treated at random with either plain saline $(\mathrm{N}=7)$ or toxin $(\mathrm{N}=8)$ as described before. Sixty minutes after injection, the test meal was administered quickly by gavage and the gavage tube was removed immediately after. Fifteen minutes after the administration of the labeled test meal, animals were killed by decapitation and the stomach and small and large bowels were isolated by consecutive ligatures at the esophagogastric, gastroduodenal, ileocecal and retosigmoidal junctions. The gut segments were excised and inserted into rubber glove fingers, where they were kept until counting, in order to avoid spillage of their contents. Each segment was counted with a gamma camera (Orbiter Stand; Siemens Gamasonics, Hoffman Estates, IL, USA). The results are reported as number of counts per minute, after discounting the background activity. The radioactivity remaining in the gastric segment is reported as percent of the sum of the counts in all gastrointestinal segments, including the stomach.

The effects of ranitidine on 6 control and 6 toxin-treated rats were also studied. Half the volume of ranitidine $(125 \mathrm{mg} / \mathrm{kg})$ or saline was injected $i v$ immediately before and 30 min after the administration of either saline or toxin. Ranitidine was a gift from Glaxo do Brasil (Rio de Janeiro, RJ, Brazil).

\section{Intestinal transit}

Intestinal transit was assessed by deter- 
mining the progression of a radioactive marker along the small and large bowels. The meal was instillated into the duodenum via a previously implanted cannula (8). Fasted rats were anesthetized with tribromoethanol (200 mg/100 g, ip), and submitted to laparotomy. A silastic tube (ID $4 \mathrm{~mm}$ ) was inserted through a midgastric incision and its distal extremity was positioned in the proximal duodenum, nearly $1.0 \mathrm{~cm}$ beyond the pylorus. A pouch suture was performed on the gastric wall to fix the cannula in the desired position. The proximal extremity of the silastic tube was brought subcutaneously to the scapular region on the back, where it was externalized and occluded. Rats were allowed to recover from surgery for 3 days until the intestinal transit study was performed. Groups of fasted rats were anesthetized with urethane and injected with either saline $(\mathrm{N}=9)$ or scorpion toxin $(\mathrm{N}=8)$ as previously described. Sixty minutes later, 10 $\mathrm{MBq}{ }^{99 \mathrm{~m}}$ technetium coupled to phytate diluted in a bolus of $1.0 \mathrm{ml}$ saline was instilled into the proximal duodenum via the implanted cannula. One hour later, the animals were killed by decapitation and specific segments of the gastrointestinal tract were isolated with ligatures and excised. The stomach and the $1.0-\mathrm{cm}$ long proximal portion of the duodenum, which contained the distal end of the cannula, comprised the first segment. The remaining small intestine was carefully removed and slightly stretched. Obstructive ligatures were then performed in order to obtain five consecutive segments of the small bowel (about $20 \mathrm{~cm}$ long) whereas the entire large bowel comprised the last segment. These 7 segments were then processed and counted as described before.

Counts obtained in individual segments were used to calculate the geometric center of the distribution of the marker throughout the gastrointestinal tract $(8,9)$. Retention of the marker in the first gastroduodenal segment was also calculated by expressing the counts obtained in this segment as a percentage of the total counts.

Since our preliminary results showed a marked transit inhibition in both toxin-treated and control animals, which might putatively be ascribed to anesthesia, a further group of 6 awake animals were studied with the same protocol.

\section{Gastric secretion}

Groups of 6 fasted rats were anesthetized and randomly treated with either saline or toxin, or a combination of toxin plus ranitidine, as described before. Sixty minutes later, the abdomen was opened and the stomach was removed after ligating the pylorus and the esophagogastric junction. The excised stomach was opened along the greater curvature and the gastric juice was collected into a small beaker for volume and acidity determinations (3). Volume was determined with a calibrated test tube and acid concentration was determined by electrometric titration against $0.05 \mathrm{~N} \mathrm{NaOH}$, using an automatic pH-meter (Corning Inc., New York, NY, USA). Acid output, expressed as $\mu \mathrm{Eq} / \mathrm{h}$, was calculated by multiplying the obtained acid concentration by the measured volume.

\section{Statistical analysis}

Data are reported as medians and range. All comparisons were performed by the Mann-Whitney U-test (10), with differences considered to be significant for values of $\mathrm{P}<0.05$.

\section{Results}

\section{General effects of scorpion toxin}

All rats treated with scorpion toxin showed signs of envenomation, including salivary hypersecretion and disturbances of respiratory rhythm, such as prolonged peri- 
Figure 1 - Gastric emptying of saline in rats treated with scorpion toxin alone ( $T X, N=8$ ), or in combination with ranitidine (TX $+\mathrm{R}, \mathrm{N}=6$ ) and in control (C) rats injected with saline $(\mathrm{N}=7)$ or ranitidine $(C+R, N=6)$. Data are individual values of the radioactivity remaining in the stomach 15 min after intragastric instillation of saline $(1.0 \mathrm{ml} / \mathrm{kg}$ body weight) labeled with $99 \mathrm{~m}$ technetium coupled to an unabsorbable carrier, expressed as percentage of total activity in the gastrointes-

tinal tract. Horizontal bars represent the medians. The doses were applied as follows: TX, $250 \mu \mathrm{g} / \mathrm{kg} ; \mathrm{R}, 2.5 \mathrm{mg} / \mathrm{kg}$. N.S., Not significant.

Figure 2 - Gastrointestinal transit of a liquid meal in urethane (U)anesthetized rats treated with scorpion toxin $(U+T X, N=8)$ or saline $(U+S, N=9)$ and in control awake $(C+S, N=6)$ rats. Data are individual values of the geometric center of the distribution of radioactivity from the stomach and proximal duodenum (segment number 1 ) up to the distal small bowel (segment number 6). Animals were studied 60 min after intraduodenal instillation of a 1.0-ml bolus of saline labeled with $99 \mathrm{~m}$ technetium coupled to an unabsorbable carrier. Horizontal bars represent the medians. The TX dose was $250 \mu \mathrm{g} / \mathrm{kg}$.

Table 1 - Percentages of the total radioactivity along the gastrointestinal tract $1 \mathrm{~h}$ after instillation into the proximal duodenum of $1.0 \mathrm{ml}$ saline labeled (S) with ${ }^{99}$ technetium coupled to an unabsorbable carrier in control awake $(C+S, N=16)$ animals and in groups of urethane $(U)$-anesthetized rats treated with scorpion toxin $(U+T X, N=8)$ or saline $(U+S, N=9)$

Radioactivity was determined in the gastroduodenal region (GD), in five consecutive segments of the small bowel (SB 1-5) and in the whole large bowel (LB). Data are reported as medians and range (in parentheses).

\begin{tabular}{cccccccc}
\hline Group & $\mathrm{GD}$ & $\mathrm{SB}_{1}$ & $\mathrm{SB}_{2}$ & $\mathrm{SB}_{3}$ & $\mathrm{SB}_{4}$ & $\mathrm{SB}_{5}$ & $\mathrm{LB}$ \\
\hline $\mathrm{C}+\mathrm{S}$ & $5(0-40)$ & $1(1-5)$ & $1(1-6)$ & $4(1-10)$ & $88(40-90)$ & $1(0-7)$ & $1(0-2)$ \\
$\mathrm{U}+\mathrm{S}$ & $16(2-92)$ & $32(2-93)$ & $13(0-70)$ & $10(0-78)$ & $0(0-1)$ & $0(0-1)$ & $0(0-1)$ \\
$\mathrm{U}+\mathrm{TX}$ & $78(4-89)$ & $22(10-58)$ & $1(0-38)$ & $0(0-1)$ & $0(0-1)$ & $0(0-0)$ & $0(0-0)$
\end{tabular}

ods of apnea, and urethral hypersecretion.

\section{Effect of scorpion toxin on gastric emptying}

Data concerning gastric emptying are presented in Figure 1. The fraction of the radiolabeled test meal found in the stomach of toxin-injected rats (median: $88 \%$; range: $52-$ $95 \%)$ was significantly greater $(\mathrm{P}<0.02)$ than in the control group $(54 \% ; 32-76 \%)$. Pretreatment with ranitidine did not affect gastric emptying in either control $(53 \%$; $32-$ $74 \%)$ or toxin-treated rats $(87 \% ; 63-93 \%)$.

\section{Effect of scorpion toxin on intestinal transit}

Data concerning the progression of the isotope marker through the gastrointestinal tract are shown in Table 1 and in Figure 2. The retention of the marker in the gastroduodenal segment in toxin-treated rats $(78 \%$; $4-89 \%)$ was significantly greater $(\mathrm{P}<0.02)$ than in controls $(16 \% ; 2-92 \%)$. In non-anesthetized rats, the activity retained in the gastroduodenal segment $(5 \%$; $0-40 \%)$ was significantly lower $(\mathrm{P}<0.02)$ than that obtained in anesthetized control animals. Data in Table 1 also show that, in awake animals, the radioactive marker progressed up to the more distal segments of the small bowel. In contrast, in anesthetized control rats, activity was detected mainly in the more proximal segments of the small bowel, thus indicating an inhibitory effect of urethane anesthesia on gastrointestinal transit. In toxin-treated rats, the radioactive marker hardly left the gastroduodenal region. Values for the geometric center (Figure 2) obtained in toxintreated animals $(1.2 ; 1.0-2.5)$ were significantly lower $(\mathrm{P}<0.05)$ than those of controls $(2.3 ; 1.0-3.2)$ and non-anesthetized rats (4.4; 2.6-4.9).

\section{Effect of scorpion toxin on gastric secretion}

Rats injected with scorpion toxin showed significantly higher $(\mathrm{P}<0.01)$ values of both 
volume (3.6 ml; 0.4-4.4 ml) and acid output $(107 \mu \mathrm{Eq} / \mathrm{h} ; 27-176 \mu \mathrm{Eq} / \mathrm{h})$ than control animals (volume: $1.0 \mathrm{ml} ; 0.3-5.6 \mathrm{ml}$ - acid output: $32 \mu \mathrm{Eq} / \mathrm{h} ; 11-91 \mu \mathrm{Eq} / \mathrm{h})$. The stimulatory effect of toxin on gastric secretion was effectively blocked by ranitidine pretreatment, since values observed in this group of animals for both volume $(0.6 \mathrm{ml} ; 0.2-1.0 \mathrm{ml})$ and acid output $(40 \mu \mathrm{Eq} / \mathrm{h} ; 16-76 \mu \mathrm{Eq} / \mathrm{h})$ were significantly lower $(\mathrm{P}<0.05)$ than those obtained with toxin only and similar $(\mathrm{P}>0.10)$ to those verified in control rats.

\section{Discussion}

The results of this study show that the injection of a purified scorpion toxin fraction in anesthetized rats is associated with marked inhibition of both gastric emptying and intestinal transit.

The slowing of gastric emptying associated with toxin injection could be produced by several motor abnormalities, such as increased gastric relaxation, decreased antral contractility or enhanced pyloric and/or duodenal resistance (11). Since the test meal used in the present study was isosmotic and did not contain nutrients, it is unlikely that this effect of the toxin was mediated through an increase in intestinal inhibition of gastric emptying. Also, the lack of effect of ranitidine rules out an influence of gastric acid hypersecretion, which might theoretically cause hyperexcitation of acid-sensitive duodenal receptors inhibiting gastric emptying (12).

The present demonstration of gastric emptying inhibition following tityustoxin injection confirms recently published data (6), which have also shown that this effect may persist for up to $48 \mathrm{~h}$ after toxin administration.

The remarkable retention of the isotope marker in the gastroduodenal region associated with substantial inhibition of intestinal transit in toxin-injected animals could be caused by either failure of propulsion or increased intestinal segmentary motor activity (11). Previous studies on isolated intestinal smooth muscle preparations showed that scorpion toxin enhances intestinal tonus and induces spastic contractions (5), which may support the view that increased small intestinal resistance plays a role in the inhibitory actions of tityustoxin on intestinal transit, as well as on gastric emptying.

Although we are aware of the effects of anesthesia on gastrointestinal functions (13), we decided to utilize urethane not only to circumvent the possibility of pulmonary edema induced by scorpion toxin in awake animals (14), but also on ethical grounds. Urethane was chosen because it seems to preserve both excitatory and inhibitory autonomic reflex responses in a variety of organs and systems (15). Despite the strong inhibitory effect of urethane anesthesia on gastrointestinal transit, which is consistent with previous findings (16), we were able to show the remarkable influence of scorpion toxin on gastric emptying and intestinal transit.

Previously published papers have demonstrated that the effects of tityustoxin on the gastrointestinal tract involve the release of both cholinergic and adrenergic mediators, as well as of other neurotransmitters, such as serotonin and substance $\mathrm{P}(17,18)$. It is therefore likely that any putative motor mechanism implicated in the inhibition of gastric emptying and intestinal transit associated with tityustoxin injection should be elicited by the release of neurotransmitters and neuromodulators. It is well known that alpha-adrenergic agents, particularly those of the alpha-2 subtype, act as potent inhibitors of gastric emptying (19) and have been proposed as a pharmacological model of gastroparesis (20). The release of other nonadrenergic, non-cholinergic mediators of gut smooth muscle relaxation, such as nitric oxide or vasoactive intestinal polypeptide (21), which are thought to be involved in the toxin-induced relaxation of isolated rat smooth muscle $(22,23)$, may also play a role 
in the production of gastrointestinal transit inhibition.

Envenomation by scorpions may cause striking cardiorespiratory and metabolic effects, which may be associated with ischemia of the gastrointestinal tract (24). Also, significant changes in serum electrolyte concentrations have been shown after envenomation, and may cause altered cell membrane permeability (25). Thus, impaired gas- tric emptying and failure of intestinal progression in toxin-injected animals may be a consequence of either systemic or local alterations affecting smooth muscle cells.

Whatever the mechanisms involved in the mediation of these effects, the present study provides evidence that delayed gastric emptying and inhibition of small intestinal transit are part of the spectrum of biological effects of scorpion toxins.

\section{References}

1. Campos J A, Silva OS, Lopez M \& FreireMaia L (1980). Signs, symptoms and treatment of severe scorpion poisoning in children. In: Eaker D \& Wadstrom T (Editors), Natural Toxins. Pergamon Press, Oxford.

2. Gonzaga HMS, Alzamora F, Cunha-Melo J R \& Freire-Maia L (1979). Gastric secretion induced by scorpion toxin. Toxicon, 17: 316-318.

3. Cunha-Melo J R, Gonzaga HMS, Alzamora F \& Freire-Maia L (1983). Effects of purified scorpion toxin (tityustoxin) on gastric secretion in the rat. Toxicon, 21: 843-848.

4. Cunha-Melo J R, Toppa NH, Martins P, Colares CN, Castro YS \& Freire-Maia L (1991). Acute gastric mucosal injury induced by toxins from Tityus serrulatus scorpion venom: a novel experimental model in the rat. Toxicon, 29: 1395-1401.

5. Cunha-Melo J R, Freire-Maia L, Tafuri WL $\&$ Maria T (1973). Mechanism of action of purified scorpion toxin on the isolated rat intestine. Toxicon, 11: 81-84.

6. Bucaretchi $F$, Vinagre AM, ChavésOlórtegui C \& Collares EF (1999). Effect of toxin- $\gamma$ from Tityus semulatus scorpion venom on gastric emptying in rats. Brazilian J oumal of Medical and Biological Research, 32: 431-434.

7. Gomez MV \& Diniz CR (1966). Separation of toxic components from the Brazilian scorpion Tityus semulatus. Memórias do Instituto Butantan, 33: 899-902.

8. Williams $\mathrm{CL}$, Villar RG, Peterson JM \& Burks TF (1988). Stress-induced changes in intestinal transit in the rat: a model for irritable bowel syndrome. Gastroenterology, 94: 611-621.

9. Miller MS, Galligan JJ \& Burks TF (1981). Accurate measurement of intestinal tran- sit in the rat. J ournal of Pharmacological Methods, 6: 211-217.

10. Siegel S (1956). Non-Parametric Statistics for the Behavioral Sciences. McGraw-Hill, New York.

11. Malagelada J -R \& Azpiroz F (1989). Determinants of gastric emptying and intestinal transit. In: Wood J W (Editor), Handbook of Physiology. The Gastrointestinal System. Section 6. Vol. I. American Physiological Association, Bethesda, 909-937.

12. Hunt J N \& Knox MT (1969). The slowing of gastric emptying by nine acids. J ournal of Physiology, 201: 161-179.

13. Schurizek BA (1991). The effects of general anaesthesia on antroduodenal motility, gastric $\mathrm{pH}$ and gastric emptying in man. Danish Medical Bulletin, 38: 347365.

14. Freire-Maia L, Almeida HO, Cunha-Melo J R, Azevedo AD \& Barroso J (1978). Mechanism of the pulmonary oedema induced by intravenous injection of scorpion toxin in the rat. Agents and Actions, 8: 113-118.

15. Maggi CA \& Meli A (1986). Suitability of urethane anesthesia for physiopharmacological investigations in various systems. Experientia, 42: 531-537.

16. Yuasa H \& Watanabe J (1994). Influence of urethane anesthesia and abdominal surgery on gastrointestinal motility in rats. Biological and Pharmaceutical Bulletin, 17: 1309-1312.

17. Freire-Maia L \& Diniz CR (1970). Pharmacological action of a purified scorpion toxin in the rat. Toxicon, 8: 132 (Abstract).

18. Hial W \& Diniz CR (1971). Efeito da escorpiotoxina sobre o conteúdo de substância $\mathrm{P}$ do intestino de rato. Ciência e
Cultura, 23 (Suppl): 304 (Abstract).

19. Sninsky CA, Davis RH, Clench MH, Thomas KD \& Mathias JR (1986). Effect of lidamidine hydrochloride and loperamide on gastric emptying and transit of the small intestine. Gastroenterology, 90: 6873.

20. Gullikson GW, Virina MA, Loeffler R \& Enwin WD (1991). Alpha-2 adrenergic model of gastroparesis: validation with renzapride, a stimulator of motility. American J ournal of Physiology, 261: G426-G432.

21. Li CG \& Rand MJ (1990). Nitric oxide and vasoactive intestinal polypeptide mediate non-adrenergic, non-cholinergic inhibitory transmission to smooth muscle of the rat gastric fundus. European J ournal of Pharmacology, 191: 303-309.

22. Gwee MC, Cheah LS \& Gopalakrishnakone P (1995). Involvement of the L-arginine-nitric oxide synthase pathway in the relaxant responses of the rat isolated anococcygeus muscle to a scorpion (Leiurus quinquestriatus quinquestriatus) venom. Toxicon, 33: 1141-1150.

23. Gong J, Kini RM, Gwee MC, Gopalakrishnakone P \& Chung MC (1997). Makatoxin I, a novel toxin isolated from the venom of the scorpion Buthus martensi Karsh exhibits nitrergic actions. J ournal of Biological Chemistry, 272: 8320-8324.

24. Sofer S, Cohen R, Shapir Y, Chen L, Colon A \& Scharf SM (1997). Scorpion venom leads to gastrointestinal ischaemia despite increased oxygen delivery in pigs. Critical Care Medicine, 25: 834-840.

25. Sofer S, Shahak E \& Gueron M (1994) Scorpion envenomation and anti-venom therapy. J ournal of Pediatrics, 124: 973978. 